\title{
Research on New University Education Management Methods based on the Combination of human and institutional
}

\author{
Ming Yuemei ${ }^{1}$ \\ ${ }^{1}$ Langfang Teachers University , \\ Langfang,Hebei Province,China
}

\begin{abstract}
In this paper, we conduct research on new university education management methods based on the combination of humanized and institutionalized. Modern university education management, system management and the organic integration of humanistic care is under the new period of development, university education management to sustainable development as the main direction of the management. System and manage all exist, man and man is the subject and purpose of system and management. The construction of system, arrangement and operation shall be at the center of the reality of human and highlight the cultural characteristics of follow the characteristic of the knowledge in the differentiation and specialization.
\end{abstract}

Keywords: Education Management; University and College; Humanized and Institutionalized.

\section{Introduction}

China's higher education has been gradually from is given priority to with scale expansion to coordinated development in order to improve the quality as the center of the stage. From the source said that in the education resources under the condition of constant, higher education quality problem in the final analysis is the management of institutions of higher learning. Institution of higher learning as an institution and an organization has the decision of the progress and quality of the main aspects in management. While the scientific management is a fundamental guarantee of higher education quality and this requires to sets up and implements the scientific concept of development in higher education management. Adhere to the people-oriented, to achieve higher education

\author{
ZhangBo ${ }^{1}$ \\ ${ }^{1}$ Langfang Teachers University, \\ Langfang,Hebei Province,China
}

comprehensive, balanced and sustainable development. The development of higher education, the first is that in the process of education to carry out the management efficiency, well-managed, various will get a more reasonable utilization of resources, talents will be more broad space for development, is the so-called person. If management is not science, then our higher education must be in "wasted effort" results.

Management to other departments of the nature, respect people, developing people, fully respect the value of people and the principle of work, thought students create more freedom and democracy, harmonious and developing environment for the primary principle, finally realizes the students' comprehensive quality and ability improvement. Actually, people-oriented in education management in colleges and universities, most of the time still reflected in some of the subtleties, it is precisely these subtleties, has affected the student life development trajectory, also identified the concept of talent cultivation. For example, a very stressed in some universities students to learn and grasp knowledge, test with teachers about what knowledge, then take an examination of what knowledge, learn good fully reflected in this paper. Many teachers also feel quite "efficient", because what he said in class who didn't listen to you certainly won't exam, so the test is equivalent to into the appraisal of teachers lecture in class, rather than course line itself connotation of knowledge evaluation. Colleges and universities are the production knowledge and disseminate knowledge in society are the most centralized place, became the most desirable place for young people but colleges and universities is not only a knowledge production, dissemination of knowledge, also should be a place of education 
which is the place where a person rich emotion, cultivate people here not only has a solid professional knowledge, must have the noble moral character, the correct outlook on life, values and morals, is rich in emotion and this talent can truly into the order of the socialist construction [1].

From the point of the external environment, with the internationalization of China's economic development, international competition need more human resources based support, prompting further deepen the reform of college education. From the point of internal environment, with the adjustment of industrial structure, the competitiveness between colleges and universities are also increasing, especially after the enrollment expansion, universities in gradually expand the scale of its enrollment, strengthening the management of the university education reform is imminent. Therefore, no matter from internal or external, university education reform and innovation of teaching management has become an important trend of social development. In management in institutions of higher learning is to seek the universities own development. The development of science must be emphasized. Any of the behavior management in the scientific concept of development must be supported by evidence and the evidence of the management behavior. But the reform of the university is not a problem, in the form of the calls for reform and innovation of from inside to outside. Therefore universities should combine their own actual situation, focused, and the behavior of preferring to focus on.

In this paper, we conduct research on new university education management methods based on the combination of humanized and institutionalized. In the current our country college education management process of the development of also is not very perfect, the system needs to be further perfect, for the development of the students and the school has a certain effect, in order to produce more high-quality talents for socialist development, completes the process reengineering, according to the theory of overall planning, is to keep up with the development of the times, but also promote the progress of the whole school. In the following sections, we will discuss the issues in detail.

\section{The Proposed Methodology}

The Principles of University Education Management. Comprehensively improve the quality of higher education, is an eternal theme for higher education enterprise development and the current and future a period of time the urgent task of the higher education reform, development and basic task. College education management system reform and innovation, also want to focus on improve the quality of higher education in this era theme and actively promote fundamental task, making university education management system and the reform of the system is more rich times features, more can reflect its safeguard and promote the development of education function. In knowledge, intelligence and physique, and skills of the students have a good improve, make professional skills more has the practical enhancement, at the same time, teachers should also be responsible for logistics educational aspects of related work, in the context of the current situation, the education environment of colleges and universities in our country are the classroom education, there is no an obvious interaction between teachers and students, students and teachers cannot have a relatively good communication, teachers understand the students' ability is in the final examination, this for talent "processing" is a kind of disadvantages, make a lot of colleges and universities can't really related experiment, the students also do not have enough experience [2].

College education process reengineering in a certain extent, should go to the market, the market as the final guidance, to cultivate students to adapt to the market demand of resources, understand the requirements of relevant unit of choose and employ persons, help students the right setting goals, to give students the right management, thus achieve the education management on the process 
reengineering, attaches great importance to the education process for the cultivation of the students have a certain importance and particularity, thus developing the students at the same time can promote the development of our country education demand and desire need for talents to improve the process to implement principle. University education management reform and innovation should pay attention to both in ideology and practice innovation synchronization. On the one hand, based on the demand of improving higher education quality promote reform and innovation of education management in colleges and universities, to continue to solve problems of ideological understanding. In this regard, both must further enhance promote reform and innovation of education management in colleges and universities, a sense of urgency to improve the quality of higher education in an all-round way and pay special attention to correctly understand and grasp the essence.

The college education management status could be summarized as the follows. (1) Management consciousness. College education management consciousness is mainly manifested in several aspects. Influenced by education mode in our country, more and more colleges and universities will be "quality of teaching, scientific research achievements" as the sole criterion for running a school, leaving school more scientific research management, thought education work is to convey the file content and requirements, work content is compared commonly simple, not many technical content, do not have to keep more attention on the education management work. At the same time, there is the phenomenon of "learning officer", most of the leadership of the work of education management is a scientific research achievement is good, but the education management is not scientific research better teaching result can be competent, affected the progress of the education.

(2) The quality of education management remains to improve. University education management related work plays an important role in the normal operation of the school, in the process of the education personnel occupies very important position, only improved the quality of education management, they can better finish the work, enhance the value of work, creating more value for the school. Current situation of university education management, to further improve the quality of education management has yet to be. Factors that affect education personnel promotion mainly constrained its development potential, most colleges and universities are still in the general state of heavy light education scientific research management and the promotion of education management personnel channel is narrow which cannot use scientific research personnel examination method. (3) Education management organization internal multifarious. Current situation of education management in colleges and universities, one of the more obvious problems is multifarious, education management organization interior in cluttered work content and so on, is not conducive to effective implementation of the job. Now working mode of the management of university education still adopts the traditional government management mode, set up the department too much bloated and the entire management personnel too much.

The Humanized and Institutionalized. In modern society, institutions of higher learning has evolved into a people-oriented core elements, is shouldering the multiple mission of education, academic and service system of "complexity", it is not present a significant order and disorder, commonness and features, determine and chaos, accurate and fuzzy, linear and nonlinear fusion, the fusion and the tension between the relationship. The humanized and institutionalized principles could be separated into the following parts. (1) The flexible management and rigid management relatively, it is not standardized, excluding the quantification and sequencing, non-institutionalized, humanized management belongs to the flexible management, flexible management with stochastic condition and humanism. Flexible management organization and establish a new system, but the system is generally framework, principle, direction, and management 
of specific process predictability low, high flexibility and variability. Flexible management attaches great importance to the environmental changes, the complexity of problem, the individual particularity and pay attention to the emotional needs of the members, psychological feelings and cultural experience. Guild generally adopts the flexible management mode. Flexible management is not equal to chaos and more is not equal to management. Flexible management based on the complexity of the basic system, the environmental variability and human uniqueness. (2) Rigid management system, rules and specific, clear and detailed, high maneuverability, high stability, stressed that "to be" and the organization running step-by-step, management has a consistent and stable, the characteristics of the same. Rigid management based on the rational principle, order principle and principle. Principle of rational thought, one can fully understand and grasp the management system, has the very good "calculation" ability, can make a perfect systems through the institutionalization of management can improve the efficiency of management. Think order is effective order principle, system is the guarantee of orderly, attaches great importance to the system design and final implementation.

Institutions of higher learning is a formal organization, legal procedures established on senior talents cultivation, profound historical responsibility of knowledge production, to provide high-end services, each college has a clear purpose of education and the cultivation of the specific goals. Especially in modern society, large scale of colleges and universities, social status, absorb resources increase, operation efficiency become one of the core indicators of university management. Therefore, institutions of higher learning management require a set of scientific and complete system, which needs to be rigid management. Internationalization of globalization under the big background of the relationship between the university and other stakeholders is more and more complex, colleges and universities in a changing environment, complex challenges. The complexity of the system calls the flexibility and adaptability of management mode, uniform management model often lose effectiveness, especially closely related with profound knowledge of creative thinking and the incompatibility of rigid system has a natural relationship [3]. As we know, knowledge discovery often is closely related to the inspiration and the system is unable to create and foresee the inspiration.

The Combined Education Management Methods. Modern university management are the main methods of using system management, system management be regulated and restricted to the student, with deepening the concept of people-oriented, management also gradually to humanistic care, colleges and universities in the security management smoothly at the same time, strive to cultivate people, so as to achieve the deeper and better management effects, closer to the education of college talents training target. System is not the opposite relationship between management and humanistic care, but has the coexistence, the correlation of education management in colleges and universities after into the humanistic care which can greatly enhance management effect and level. But we must see, system management and humanistic care not directly, the seamless integration between needs certain development process. In the early stage of education management in colleges and universities need to strengthen institutional management under the premise of according to the development of the process of change, appropriate rich management means. When the average development of university management on the right track, a higher level, more easily also appear all kinds of management issues at this time, the traditional management way is hard to work, humanistic care is very important for the utility, from the thought and the emotion between students and establish a sense of caring, lets the student in the self-encouragement approaches on behavior more in line with the college management requirements, system management and humanistic care organic integration. Through the combination of the humanized and 
institutionalized, our management will achieve better performance.

\section{Conclusion}

In this paper, we conduct research on new university education management methods based on the combination of humanized and institutionalized. Institutions of higher learning is an organization that scholars intensive. Intellectuals in colleges and universities, is the main part of the school, they in the construction and development of colleges and universities play an important role, at the same time, intellectuals, especially high-level intellectuals generally have high sense of mission and sense of responsibility, has the high self-discipline and self-consciousness, has a strong willingness to participate in management, and has high participation in management and self-management consciousness and ability. System flexibility and humanity, flexible management is the important condition of scholars' initiative into full play which will be beneficial for the development.

\section{References}

[1] Gao X, University C N. From Problem to Researcher: Reevaluation of Methods to Educational Research-Reflection on Argument of Problem Determining Methods[J]. Modern Education Management, 2014.

[2] Wang W Z. A Probe into Intercultural Teaching Management Methods of Foreign Teachers in University[J]. Theory \& Practice of Education, 2015.

[3] Zhang C. Implications of Basketball League System and Training Methods in Colleges and Universities in the United States[J]. Journal of Capital University of Physical Education \& Sports. 